\title{
A study in vivo of adrenergic receptors in the rectum and in the internal anal sphincter of the cat ${ }^{1}$
}

\author{
R. KERREMANS AND F. PENNINCKX \\ From the Heelkunde Gastro-enterologie, Akademisch Ziekenhuis, St Rafaël, Leuven, Belgium
}

SUMMARY The smooth muscle sphincteric activity of the anus in cats is based on two distinct mechanisms: a typical anal component, characterized by anal slow pressure waves not related to spike potentials in the internal anal sphincter, and an intestinal-like pressure component related to spiking activity in the internal sphincter. Anal slow pressure waves are influenced by the activity of alpha excitatory receptors within the internal sphincter, whereas no conclusive data are available concerning the action of adrenergic beta receptors on this pressure component. Intestinal-like pressure waves and the correlated spiking activity in the internal anal sphincter are influenced by alpha and beta inhibitory adrenergic receptors. The rectal wall of the cat contains alpha and beta adrenergic receptors producing relaxation.

The characteristics of anal pressure waves and the extracellular electrical activity of the internal anal sphincter in man have been reported earlier (Kerremans, 1968; Wankling, Brown, Collins, and Duthie, 1968). The purpose of this paper is to report the effects of adrenergic stimulating and blocking agents on (1) the motility pattern of the rectum and anal canal of the cat after elimination of all nervous transmission to the striated anal sphincter apparatus, and (2) on the electrical activity in vivo of the rectum and internal anal sphincter in the same animal. Reports of previous investigations indicate the presence of alpha and beta inhibitory adrenergic receptors in the intestine (Ahlquist and Levy, 1959; Bucknell and Whitney, 1964; Brody and Diamond, 1967), whereas alpha excitatory and beta inhibitory receptors occur in sphincters, eg, the cardiac sphincter (Ellis, Kauntze, and Trounce, 1960; Clark and Vane, 1961), the sphincter of Oddy (Crema and Berté, 1963), and the iliocaecocolic sphincter (Gazet and Jarrett, 1964; Jarrett and Gazet, 1966). The influence of drugs has

${ }^{1}$ The contents of this paper form part of a thesis, 'Morphological and physiological aspects of anal continence and defaecation' submitted by $\mathbf{R}$. Kerremans in 1969 for the degree of 'geaggregeerde van het Hoger Oonderwijs'.

Received for publication 14 November 1969. been tested previously only in vitro on the internal anal sphincter (Parks and Fishlock, 1967; Friedmann, 1968), and no data of investigations in vivo are available.

\section{Methods}

CHOICE OF ANIMALS

Cats of either sex weighing from 2.5 to $4 \mathrm{~kg}$ were studied. Cats were used because they possess an anatomically well defined smooth muscle internal sphincter which allows a more exact siting of electrodes. Cats were also chosen because they exhibit a functional internal sphincteric activity characterized by the presence of a high pressure zone, persisting after curarization, and by a marked pressure fall following rectal distension, the recto-sphincteric relaxation reflex (Gaston, 1948; Schuster, Hendrix, and Mendeloff, 1963).

\section{RECORDING OF PHYSIOLOGICAL}

PHENOMENA

The pressure in the anal canal and rectum was recorded by means of micro-balloons and by 
simultaneous captation of electrical activity at the level of the internal sphincter and rectum with silver-wire electrodes (Kerremans, 1968). The respiratory movements and ECG were recorded at the same time.

\section{PHARMACOLOGICAL INVESTIGATION}

The same drugs used by Levy (1967) were administered to the cats. Atropine $1 \mathrm{mg} / \mathrm{kg}$ and morphine $10 \mathrm{mg} / \mathrm{kg}$ were injected subcutaneously, followed by pentobarbital sodium $30 \mathrm{mg} / \mathrm{kg}$ intravenously or intraperitoneally. In addition, decamethonium $1 \mathrm{mg} / 15 \mathrm{~kg}$ was injected in a number of experiments in order to eliminate anal pressure components due to the continuous activity of the striated external anal sphincter, which was followed on electromyograms. Anal pressure patterns recorded during experiments under deep pentobarbital anaesthesia are comparable to those performed during associated curarization. To investigate the characteristics of the adrenergic receptors, two approaches have yielded most of the present knowledge (Moran, 1966). One is based upon the structure-activity relationship of agonists (Ahlquist, 1948), the other on the specificity of blocking drugs. The latter is the most conclusive until now.

In the present study adrenergic stimulation was performed by means of successive intravenous administration of adrenaline, noradrenaline, and isoprenaline. Timing of the injections was dependent on the effects of each drug on the ECG and on its influence on the anal pressure recordings. The effect commonly disappeared in about one minute. After the effect of administering the drugs had been noted, a single adrenergic blocking agent (alpha or beta) was administered, followed by further doses of catecholamines. A slow intravenous infusion of phenoxybenzamine, 0.5 or $3 \mathrm{mg} / \mathrm{kg}$, was used as the alpha-adrenergic blocking agent. A period of one hour was kept between the onset of the adrenergic blockade and the successive adrenergic stimulation in order to obtain a good blocking effect. Propanolol was used as beta-receptor blocking agent. An initial dose of $0.5 \mathrm{mg} / \mathrm{kg}$ was given, followed by a continuous infusion of $2.5 \mu \mathrm{g} / \mathrm{kg} /$ minute.

The drugs used were adrenaline hydrochloride (A), noradrenaline bitartrate (NA), isoproterenol hydrochloride (isoprenaline, isopropylnoradrenaline, INA), phenoxybenzamine hydrochloride, propanolol hydrochloride. Doses of the drugs refer to the dose of the salt in $\mu \mathrm{g}$ or $\mathrm{mg} / \mathrm{kg}$.

\section{Results}

MECHA NICAL AND ELECTRICAL ACTIVITY OF THE RECTUM AND INTERNAL ANAL SPHINCTER AT REST

Low amplitude pressure waves were recorded intermittently in the rectum. When rhythmical activity was present it was related to bursts of spike potentials in the rectal wall, and the frequency varied from 2 to $5 \mathrm{c}$ per minute. Definite electrical slow waves were not often observed but, when present, theirfrequency was between two and 10 per minute.

At the level of the anal canal, a characteristic pressure pattern was recorded during the resting state consisting of a baseline pressure on which phasic contractions with a frequency of 12 to $30 / \mathrm{min}$ were superimposed. They occurred mostly in a continuous fashion, and had similar features to the anal slow pressure waves recorded in humans. We refer to them subsequently as 'anal slow pressure' waves. Intermittently, the baseline pressure' showed low-amplitude pressure changes at the rate of two to five per minute and usually lasting more than 10 seconds, appearing intermittently. We refer to these as 'intestinallike pressure' waves. Both types of anal motility could occur either simultaneously or separately (Fig. 1a).

Electrical recordings at the level of the internal anal sphincter of the cat can be considered as the superimposition of two types of activity. The first type of electrical activity consists of continuous slow waves of variable configuration and with a frequency between 15 and 30 per minute. This is comparable to the basic electrical rhythm recorded in the internal sphincter in man. Bursts of spikes or isolated action potentials were recorded discontinuously or in a more regular fashion. The frequency of firing was about the same as the one recorded in the rectal wall. This type of activity was not recorded in human internal sphincter (Kerremans, 1968). A clear relationship between spike activity and the appearance of the intestinal-like pressure waves was observed, whereas no relation between spike potentials and the anal slow pressure waves could be observed (Fig. 1a).

INFLUENCE OF CATECHOLAMINES ON THE MECHANICAL AND ELECTRICAL ACTIVITY OF THE RECTUM

The administration of adrenaline, noradrenaline, or isoprenaline results in a slight decrease in baseline pressure in the rectum (Fig. 1b, c, and d). If rectal motility and spiking activity in the rectal wall are present at the time when the drug is given they too are inhibited. A rather long time interval, ie, 20-40 sec, occurs between the beginning of the injection and its effect on rectal pressure. None of these inhibitory effects of the adrenergic drugs can be blocked by alpha- or beta-blocking agents only given separately.

INFLUENCE OF CATECHOLAMINES ON THE MECHANICAL ACTIVITY OF THE ANUS AND ON THE ELECTRICAL ACTIVITY OF THE

INTERNAL ANAL SPHINCTER

Administration of adrenaline or noradrenaline 


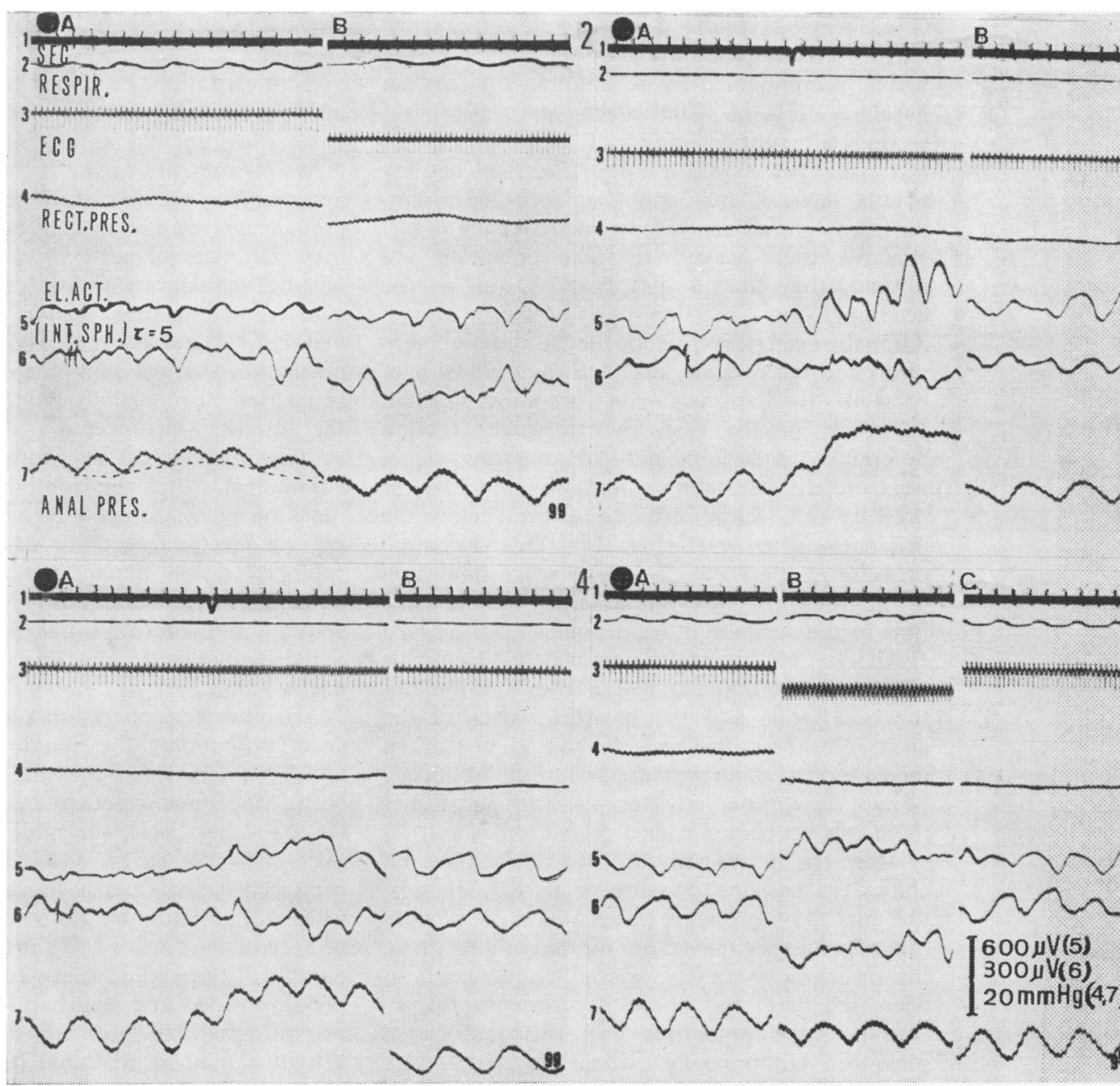

Fig. 1 Basic patterns of rectal and anal sphincteric activity and the influence of catecholamines. Seven tracings were made simultaneously and are indicated on the first record: 1 ,

time in seconds; 2 , respiration; $3, E C G ; 4$, rectal pressure (calibration in the right inferior angle $=$ $20 \mathrm{mmHg}$ ); 5 and 6, electrical activity in the internal anal sphincter (calibration $=600 \mu \mathrm{V}$, time constant, $\tau=5 \mathrm{sec}$, and calibration $=300 \mu \mathrm{V}$, time constant, $\tau=5 \mathrm{sec}) ; 7$, pressure in the anal canal (calibration $=20 \mathrm{mmHg}$ ). The arrows on the time tracings indicate the end of drug administration. (a) tracings in the resting state. Note the superimposition of anal slow pressure waves and intestinal-like pressure waves in $1 A$ and only anal slow pressure waves in $1 B$. (b) and (c) administration of adrenaline ( (b) A) and of noradrenaline ( (c) $A$ ) both result in a sudden increase of frequency of the anal slow pressure waves, without spiking, of frequency of the anal slow pressure waves, without spiking activity in the internal anal sphincter. (b) $B$ and (c) $B$ are taken one minute after drug administration. (d) isoprenaline administration (just before (d) B) does not affect the anal slow pressure waves but lowers overall anal pressure. The rectal pressure is also decreased. (d) $C$ is taken one minute after injection of INA. 
(Fig. 1b and c) results in an increase in frequency and a decrease in amplitude of anal slow pressure waves, accompanied by a simultaneous rise in baseline pressure. The effects start 10 to 15 seconds after the beginning of the injection, and last usually for one minute. Electrical activity of the internal anal sphincter recorded simultaneously shows an increase in frequency of the slow electrical waves. If spike potentials are present, they always disappear as well as the accompanying intestinal-like pressure waves. After the excitatory period, the baseline pressure returns to the original level and the frequency of pressure oscillations again becomes normal. However, in the cases where spikes (action potentials) and intestinal-like pressure waves were present just before stimulation the baseline pressure falls temporarily to a level below the original resting level (Fig. 1c). This decreased pressure is related to prolonged spike inhibition in the internal anal sphincter and lasts the same time as the decrease in rectal tone.

Analysis of the results obtained in 13 animals (Table) shows that adrenaline always stimulates the basal tone and the pressure waves of the anus. Noradrenaline usually caused a marked increase of baseline pressure and of the frequency of anal slow pressure waves, although sometimes there was no response or a relaxation.

After the administration of isoprenaline no change in baseline pressure or in frequency of the anal slow pressure waves occurred in eight out of 17 experiments. In the remaining cases, the mechanical activity was either increased or decreased (six and three experiments respectively). Spike potentials and their associated pressure components, when present, were always inhibited. The influence of INA on the electrical slow waves of the internal sphincter was variable.

Administration of the alpha-blocking agent phenoxybenzamine resulted in a lowering of anal basal pressure and a decrease in frequency of anal slow pressure waves. If these slow waves disappear the records show only intestinal-like pressure waves and spiking activity. The excitatory responses of adrenaline and noradrenaline on anal basal pressure and on the frequency of anal slow pressure waves are abolished or markedly decreased after the administration of phenoxybenzamine (Fig. 2a and b). Phenoxybenzamine also partially blocks the inhibition of the intestinal-like pressure waves and spiking activity produced by adrenaline and noradrenaline. After the administration of alphablocking agent, isoprenaline has no uniform effect on the electrical activity of the internal anal sphincter or on the mechanical activity of the anus. However, its inhibitory action on spike activity and on intestinal-like pressure waves remains unaltered. The results are summarized in the Table.

After the administration of the beta-blocking agent propanolol, the excitatory influence of $\mathbf{A}$ and NA on anal slow pressure waves and on anal basal tone remained unaltered (Fig. $2 d$ and e). On the other hand, the inhibition of intestinallike pressure waves and of spiking activity produced by $\mathbf{A}$ is partly blocked by propanolol, whereas the inhibitory action of NA appeared to be accentuated. After the administration of propanolol, isoprenaline rarely influenced anal slow pressure waves and anal basal tone. Its influence on intestinal-like pressure waves and spiking activity remained unaltered or was only slightly reduced (Fig. 2b).

\begin{tabular}{|c|c|c|c|c|c|c|c|c|c|c|c|c|}
\hline \multirow[t]{3}{*}{ Drug } & \multicolumn{8}{|c|}{ Anal Motility } & \multirow{2}{*}{\multicolumn{4}{|c|}{$\begin{array}{l}\text { Electrical Activity of Internal Anal Sphincter } \\
\text { Spiking Activity }\end{array}$}} \\
\hline & \multicolumn{4}{|c|}{ Anal Slow Pressure Waves and Basal Tone } & \multicolumn{4}{|c|}{ Intestinal-like Pressure Waves } & & & & \\
\hline & Excitation & No Effect & Inhibition & $\begin{array}{l}\text { Total No. of } \\
\text { Experiments }\end{array}$ & Excitation & No Effect & Inhibition & $\begin{array}{l}\text { Total No. of } \\
\text { Experiments }\end{array}$ & Excitation & No Effect & Inhibition & $\begin{array}{l}\text { Total No. of } \\
\text { Experiments }\end{array}$ \\
\hline \multicolumn{13}{|c|}{ Responses to catecholamines } \\
\hline A & 13 & & & 13 & & 6 & 6 & 12 & & 4 & 8 & 12 \\
\hline NA & 17 & 2 & 1 & 20 & & 11 & 3 & 14 & & 12 & 7 & 19 \\
\hline INA & 6 & 8 & 3 & 17 & & 9 & 5 & 14 & & 8 & 9 & 17 \\
\hline \multicolumn{13}{|c|}{ Responses to catecholamines after administration of alpha-blocking agent } \\
\hline Alpha block & & 1 & 5 & 6 & 2 & 3 & & 5 & 2 & 4 & & 6 \\
\hline$+\mathbf{A}$ & & 10 & & 10 & & 6 & 4 & 10 & & 7 & 3 & 10 \\
\hline +NA & & 9 & & 9 & 1 & 6 & 2 & 9 & 1 & 6 & 2 & 9 \\
\hline+ INA & 2 & 7 & 7 & 16 & & 4 & 9 & 13 & & 7 & 8 & 15 \\
\hline \multicolumn{13}{|c|}{ Responses to catecholamines after administration of beta-blocking agent } \\
\hline Beta block & 2 & 3 & 3 & 8 & 7 & 1 & & 8 & 6 & 2 & 1 & 9 \\
\hline$+\mathbf{A}$ & 7 & 1 & & 8 & & 4 & 1 & 5 & 1 & 4 & 3 & 8 \\
\hline +NA & 7 & 2 & & 9 & & 1 & 3 & 4 & & 4 & 4 & 8 \\
\hline +INA & & 7 & 1 & 8 & & 3 & 1 & 4 & & 3 & 4 & 7 \\
\hline
\end{tabular}

Table Results of pharmacological investigations on anal motility and electrical activity in the internal anal sphincter in the cat ${ }^{1}$

${ }^{1}$ Each experiment is in a different cat. 


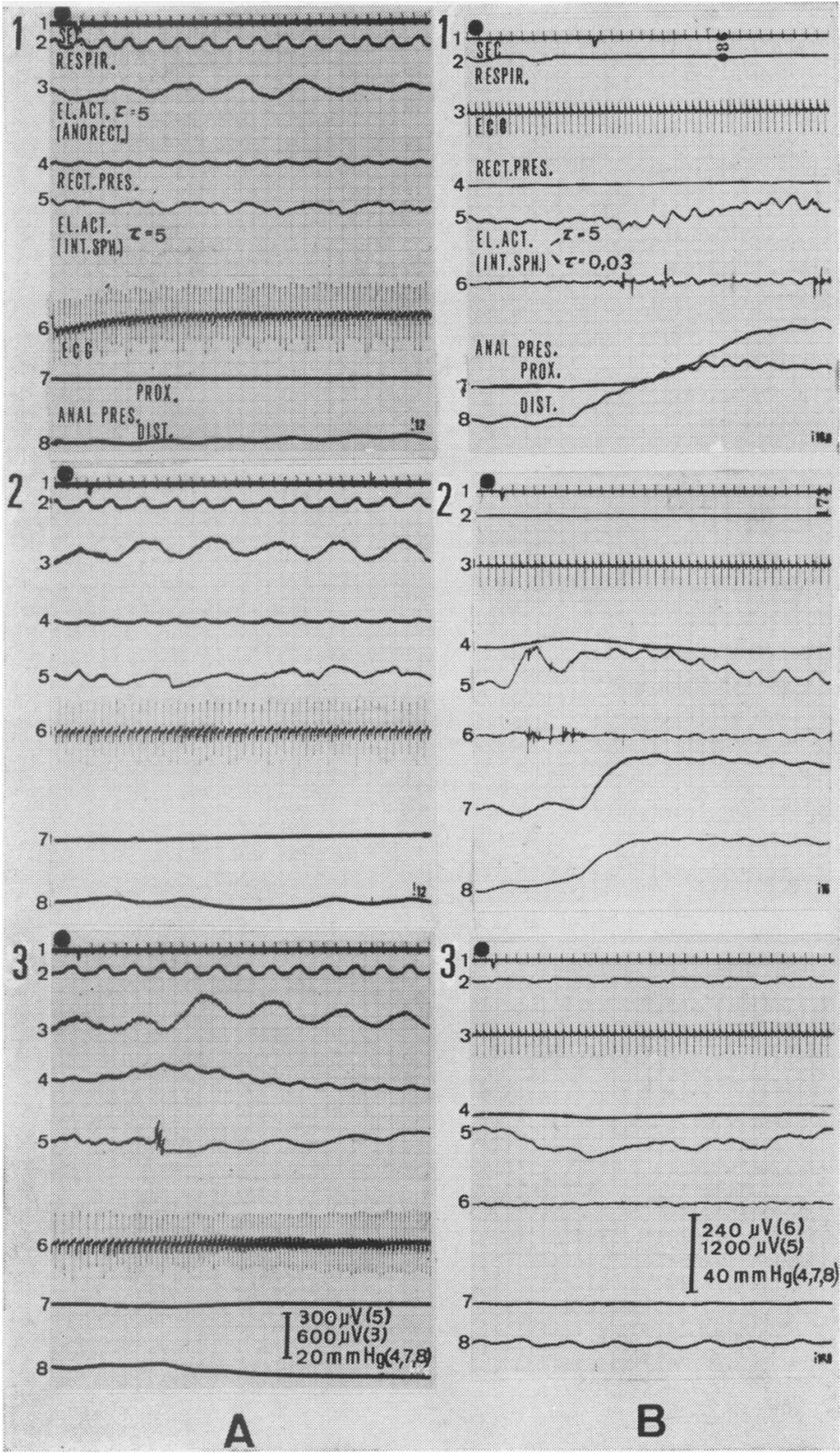

Discussion and Conclusion

Our results indicate that the properties of the adrenergic receptors in the rectum are identical to the ones observed at other levels of the intestine (Ahlquist and Levy, 1959; Bucknell and Whitney, 1964; Levy, 1967). We may therefore assume that alpha- and beta-inhibitory receptors are present in the wall 'of the rectum. The effects of adrenergic stimulating and blocking agents support our conception concerning the physiological behaviour of the anal autonomous apparatus in the cat at rest; that is to say, after excluding the function of the striated sphincter, two separate physiological mech-
Fig. 2 Influence of adrenergic blocking agents on responses to catecholamines.

(a), (b), and (c): Influence of alpha-receptor blockade on responses to catecholamines. Eight tracings were made simultaneously and are indicated on the first record. Tracing 1, time in seconds; 2 , respiration; 3 , electrical activity at the ano-rectal junction (calibration at the bottom $=600 \mu \mathrm{V}$, time constant, $c=5 \mathrm{sec}$ ); 4 , rectal pressure (calibration = $20 \mathrm{mmHg}$ ); 5 , electrical activity in the internal anal sphincter (calibration $=300 \mu \mathrm{V}$, time constant, $c=5 \mathrm{sec}) ; 6, E C G ; 7$, pressure in the proximal part, and 8 , pressure in the distal part of the anal canal (calibration $=20 \mathrm{mmHg}$ ). The arrows on the time tracings indicate the end of drug administration. Phenoxybenzamine abolishes the excitatory action of adrenaline (a) noradrenaline (b) on anal pressure. Administration of isoprenaline after phenoxybenzamine (c) results in an inhibition of intestinal-like pressure waves in the anal canal, inhibition of spike activity in the internal anal sphincter and of rectal motility.

(d), (c) and (f): Influence of beta-blockade on responses to catecholamines. Eight tracings were made simultaneously and are indicated on the first record. Tracing 1, time in seconds; 2, respiration; 3, ECG; 4, rectal pressure (calibration at the bottom $=40 \mathrm{mmHg}$ ); 5 and 6 , electrical activity in the internal anal sphincter (calibration $=$ $1.200 \mu \mathrm{V}$, time constant, $c=5 \mathrm{sec}$, and calibration $=$ $240 \mu \mathrm{V}$, time constant, $c=0.03 \mathrm{sec}$ ); 7 , pressure in the proximal part, and 8, pressure in the distal part of the anal canal (calibration $=40 \mathrm{mmHg}$ ). The arrows on the time tracings indicate the end of the drug administration. The effects of adrenaline (d) and noradrenaline (e) on anal slow pressure waves and on basal tone are not modified by previous administration of propanolol. Isoprenaline after propanolol (f) does not change anal slow pressure waves.

anisms can be distinguished in the pressure pattern recorded in the anal canal of the cat. There are anal slow pressure waves which are independent of spiking activity and intestinallike pressure waves which are related to spiking activity within the internal anal sphincter. Both mechanisms react in a different manner to adrenergic stimulating and blocking agents. Dissociation and interpretation of both mechanisms was only possible by studying the electrical activity in the internal anal sphincter recorded simultaneously with the pressure in the anal canal. The analysis of the results shows that the anal slow pressure wave frequency and the level of the baseline pressure are both influenced by 
the activity of alpha excitatory adrenergic receptors. Our findings in vivo on the role of the beta receptors in the regulation of anal slow pressure waves and basal tone are not conclusive, but it seems that they have an inhibitory action on these waves and on the basal tone. Although the influence of isoprenaline stimulation without previous administration of adrenergic blocking agents varied, in seven out of $16(44 \%)$ stimulations with isoprenaline after alpha blockade an inhibitory effect was observed (Table). This inhibition was prevented by previous beta blockade in seven out of eight experiments. The excitatory effect observed with isoprenaline in six out of 17 experiments was reduced after the administration of alpha blocking agent. This stimulation of alpha receptors might be due to catecholamines released reflexly into the bloodstream as a result of isoprenaline-induced hypotension. In our opinion this hypothesis could explain why the existence of beta inhibitory receptors is difficult to prove in studies in vivo. The mechanism of excitation by INA after alpha receptor blockade in two out of 16 experiments remains obscure.

It nevertheless appears that both the anal intestinal-like pressure component in vivo and the accompanying spiking activity in the internal sphincter of the cat are influenced by the activity of alpha and beta inhibitory adrenergic receptors. These pressure waves apparently have the same properties as those recorded in the rectum and their reaction to the administration of the drugs is also identical.

\section{References}

Ahlquist, R. P. (1948). A study of the adrenotropic receptors. Amer. J. Physiol., 153, 586-600.

Ahlquist, R. P., and Levy, B. (1959). Adrenergic receptive mechanism of canine ileum. J. Pharmacol. exp. Ther., 127, 146149.
Brody, T. M., and Diamond, J. (1967). Blockade of the biochemical correlates of contraction and relaxation in uterine and intestinal smooth muscle. Ann. N.Y. Acad. Sci., 139, 772-780.

Bucknell, A., and Whitney, B. (1964). A preliminary investigation of the pharmacology of the human isolated taenia: coli preparation. Brit. J. Pharmacol., 23, 164-175.

Clark, C. G., and Vane, J. R. (1961). The cardiac sphincter in the cat. Gut, 2, 252-262.

Crema, A., and Berté, F. (1963). Action of sympathomimetic drugs on the isolated junction of the bile duct and duo- $\frac{\bar{c}}{\sqrt{5}}$
denum. Brit. J. Pharmacol., 20, 221-229.

Daniel, E. E. (1965). The electrical and contractile activity of the $\mathbb{\mathbb { Q }}$ pyloric region in dogs and the effects of drugs. Gastroenterology, 49, 403-418.

Ellis, F. G., Kauntze, R., and Trounce, J. R. (1960). The innervation of the cardia and lower oesophagus in man. 0 Brit. J. Surg., 47, 466-472.

Friedmann, C. A. (1968). The action of nicotine and catecho- $\vec{\omega}$ lamines on the human internal sphincter. Amer. J. dig. Dis., 13, 428-431.

Gaston, E. A. (1948). The physiology of faecal continence. Surg. Gynec. Obstet., 87, 280-990.

Gazet, J. C., and Jarrett, R. J. (1964). The ileocaeco-colic sphincter $\overrightarrow{-}$ Studies in vitro in man, monkey, cat and dog. Brit. J. $\infty$ Surg., 51, 368-370.

Goodman, L. S., and Gilman, A. (1965). The Pharmacological Basis of Therapeutics, 3rd edition. Macmillan, New York.

Jarrett, R. J., and Gazet, J. C. (1966). Studies in vivo of the ileocaeco-colic sphincter in the cat and dog. Gut, 7, 271- 275.

Kerremans, R. (1968). Electrical activity and motility of the internal anal sphincter. An in vivo electrophysiologicake study in man. Acta gastro-ent. belg., 31, 465-482.

Kerremans, R. (1969). Morphological and Physiological Aspects of Anal Continence and Defaecation. Arscia Uitgaven, $\vec{\theta}$ Brussels.

Levy, B. (1967). Adrenergic receptors in intestinal smooth? muscle. Ann. N.Y. Acad. Sci., 139, $781-787$.

Moran, N. C. (1966). Pharmacological characterization of

adrenergic receptors. Pharmacol. Rev., 18, 503-512.
Parks, A. G., and Fishlock, D. J. (1967). Catecholamines. Proc. roy. Soc. Med., 60, 217.

Schuster, M. M., Hendrix, T. R., and Mendeloff, A. I. (1963). ํํำ The internal anal sphincter response: manometric studies on its normal physiology, neural pathways and alteration in bowel disorders. J. clin. Invest., 42, 196-207.

Wankling, W. J., Brown, B. H., Collins, C. D., and Duthie, H. L. Basal electrical activity in the anal canal in man. Gut, 9, 457-460. 
Notes and activities study. (Hans Huber, Berne, Switzerland: Fr 48, D.M. 43.)

\section{Correction}

Dr R. Kerremans (A study in vivo of adrenergic receptors in the rectum and in the internal anal sphincter of the cat', Gut, 11, 709-714) writes: Fig. 1. The large numerals 1 and 3 were not placed on the photograph, and in the legend and in the

New Officers of the New British Society of Gastroenterology

The following new officers have been elected for 1971.

PRESIDENT: Professor A. A. Harper

PRESIDENT-ELECT: Professor W. I. Card

HONORARY TREASURER: Professor C. G.

Clark

HONORARY SECRETARIES:

Dr R. Holmes

Mr Ian McColl

CHAIRMAN OF THE EDUCATION SUB-COMMitTeE: Professor B. N. Brooke

MEMBERS OF COUNCIL:

Sir Francis Avery Jones

Dr J. E. Lennard-Jones

$\mathrm{Mr}$ H. B. Torrance

The Oesophagus: A Course under the Auspices of the American Gastroenterological Association

Members of the American Gastroenterological Association will give a course on the oesophagus on 9,10 and 11 May 1971 at the Americana Hotel, Miami Beach, USA. The course on the oesophagus will precede the annual meeting of the American Gastroenterological Association.

All physicians are welcome. The registration fee is $\$ 100.00$ ( $\$ 25.00$ for students and others in training) Please address all enquiries to Mrs Frances T. Chalmers, A.G.A. Postgraduate Course, Box 190, McLean, Va. 22101.

Symposium on Intestinal Absorption and its Derangements

A symposium of interest to gastroenterologists has been arranged by the Royal College of Pathologists for Thursday and Friday, 18 and 19 February 1971, at the Royal College of Physicians, London. The subject is intestinal absorption and its derangements. The symposium is open to workers in all disciplines connected with the subject. The registration fee is $£ 8$ (sterling), which includes coffee, lunch, and tea on the two days, and a copy of the papers which are to be published as a special supplement (edited by A. M. Dawson) to the Journal of Clinical Pathology. Further information and application forms can be obtained from The Royal College of Pathologists, 2 Carlton House Terrace, London, SW1.

\section{In Commemoration of Sir Arthur Hurst}

To commemorate the founder of their Society in 1937, the British Society of Gastroenterology has published 'The selected writings of Sir Arthur Hurst', who was born in 1879 and died in 1944. Sir Arthur's original work in 1907, using bismuth and the then new ' $x$ rays', was a starting point in modern gastroenterology, and his many papers include a classical account of achalasia, and others on such subjects as carbohydrate intestinal dyspepsia, constipation and disorders of the colon, as well as on more general topics, particularly his 'War neuroses'.

Sir Arthur was a stimulating physician, fertile with ideas, and the British Society has wished to ensure that his name and work are not forgotten. The selected works are edited-with a biographical introduction-by one of the Society's past presidents, Dr Thomas Hunt, and can be obtained from the Publishing Manager, BMA House, Tavistock Square, London WC1H 9JR, price $£ 2$ (30s to members of the Society).

\section{Hepatic Failure}

Henry Brown, who is Assistant Professor of Surgery at the Harvard Medical School, has just published a short monograph on 'Hepatic failure' (published by Charles C. Thomas, Springfield, Ill. in their American Lecture Series, price $\$ 10.50$ ). The metabolism of the liver and its functions are discussed and also some of the surgical aspects of ascites and hepatic transplantation.

\section{Diseases of the Rectum and Anus}

This is a paper-bound volume written in German by two Swiss gastroenterologists, Hans Stirnemann and Fred Halter. It is a fairly small book of 253 pages. On the whole the picture of treatment is somewhat outmoded for the British proctologist, and this impression is reinforced in the rather unbalanced presentation of available methods in the surgical treatment of rectal cancer. However, for a postgraduate student this book provides a reasonable introduction to proctology, and the excellent references should stimulate further text $(a),(b),(c),(d)$ refer to these and to the large numerals 3 and 4 . Fig. 2. In the legend and in the text the letters $(a),(b),(c)$ refer to $\mathrm{A} 1, \mathrm{~A} 2, \mathrm{~A} 3$ on the figure. The letters $(d),(e),(f)$ refer to B1, B2, B3 on the figure. 